\title{
PENENTUAN SIFAT MAGNETIK PASIR DAN DEBUSEPANJANG JALAN KARTAMA KOTA PEKANBARU MENGGUNAKAN MAGNETIC PROBE PASCO PS-2162
}

\author{
Maria Sonya Nauli Nainggolan*, Erwin, Yanuar, Usman Malik \\ Program Studi S1 Fisika FMIPA, Universitas Riau \\ *E-mail korespondensi: maria.sonya7958@student.unri.ac.id
}

\begin{abstract}
Topsoil is the recipient of various kinds pollutants, especially heavy metals. Heavy metals have been detected in sand and dust along the highway. Measuring the magnetic properties of road sediment along Kartama road in Pekanbaru City has been done. The magnetic properties measured are magnetic degree, magnetic and mass susceptibility using magnetic induction measurement. The Samples were taken at sixteen locations with the amount of 1 or $2 \mathrm{~kg}$ for each point location, the samples were named as samples $1-6,7 a-7 e, 8 a-8 e$. The magnetic particles of the samples were separated from sand and dust using Iron Sand Separator and later using Neodymium Iron Boron (NdFeB) magnet. The total magnetic induction of the samples and concentrates were measured using Pasco Magnetic Probe PS-2162. In order to measure the magnetic induction of the samples, a solenoid of $3 \mathrm{~cm}$ in diameter, length of $10 \mathrm{~cm}$ and 2000 of windings was made. The empty solenoid magnetic induction was measured as a function of applied current ranging from 2-10 A and as a function of horizontal distance of 1-5 mm from the the solenoid ends. Total magnetic induction (samples and concentrates) was measured for the applied currents of 6 A. The results showed that the highest magnetic degree obtained from the sample number $7 e$ that is $2.54 \%$ and the lowest level obtained from the sample number 3 that is $0.17 \%$. The highest magnetic susceptibility value obtained from the sample number $7 b$ was is $9158.12 \times 10^{-5}$, and the lowest magnetic susceptibility value obtained from the sample number 2 with the value of $3125.52 \times 10^{-5}$. Based on the mass susceptibility values of the concentrate obtained that the sand and dust along the road Kartama Pekanbaru which are in the interval $4.6 \times 10^{-7}$ to $8.0 \times 10^{-7}$, they implies that the mass susceptibility of the samples is in the range of Ilmenite phase $\mathrm{FeTiO}_{3}$ or antiferromagnetic.
\end{abstract}

Keywords: Road sediment,magnetic induction, magnetic degree, magnetic susceptibility, mass susceptibility.

\begin{abstract}
ABSTRAK
Permukaan tanah lapisan atas merupakan penerima berbagai macam polutan terutama logam berat, logam berat sudah banyak terdeteksi pada pasir dan debu di sepanjang jalan raya. Penelitian tentang pengukuran sifat magnetik pasir dan debu disepanjang jalan Kartama Pekanbaru telah dilakukan. Sampel yang diambil di enam belas titik lokasi masing-masing massanya 1 atau $2 \mathrm{~kg}$, sampel tersebut dinamai sampel 1-6, 7a-7e, $8 a-8$ e. Pemisahan antara konsentrat dengan pasir dan debu dilakukan menggunakan Iron Sand Separator. Selanjutnya pemisahan dilakukan kembali menggunakan magnet Neodymium Iron Boron (NdFeB). Induksi magnetik total dari konsentrat diukur menggunakan Magnetik Probe Pasco PS-2162. Pengambilan data induksi magnetik dari sampel menggunakan solenoid dengan diameter $3 \mathrm{~cm}$, panjang $10 \mathrm{~cm}$, dan jumlah lilitan sebanyak 2000. Induksi magnetik solenoid tanpa inti diukur sebagai fungsi arus dengan interval 2-10 A dan sebagai fungsi jarak 1-5 mm dari ujung tengah solenoid. Induksi magnetik total (sampel dan konsentrat) diukur menggunakan arus 6 A. Hasil penelitian menunjukkan bahwa nilai tingkat kemagnetan tertinggi berasal dari sampel 7 e yaitu sebesar 2,54\% dan terendah berasal dari sampel ketiga yaitu sebesar 0,17\%. Nilai suseptibilitas magnetik tertinggi berasal dari sampel 7 b yaitu $9158,12 \times 10^{-5}$, dan nilai suseptibilitas magnetik terendah berasal dari sampel 2 yaitu 3125,52 $\times 10^{-5}$. Berdasarkan nilai suseptibilitas massa dari konsentrat yang diperoleh bahwa pasir dan debu yang berada di sepanjang jalan Kartama Pekanbaru berada dalam interval 4,6 $610^{-7}$ sampai $8,0 \times 10^{-9} \mathrm{~m}^{3} / k$, yang berarti nilai suseptibilitas massa dari masing-masing titik lokasi berada pada interval partikel Ilmenite $\mathrm{FeTiO}_{3}$ atau antiferromagnetik.
\end{abstract}

Kata kunci: Sedimen jalan,induksi magnetik, tingkat kemagnetan, suseptibilitas magnetik, suseptibilitas massa. 


\section{PENDAHULUAN}

Sebagai salah satu Negara wilayah tropis, Indonesia memiliki potensi pertanian yang sangat baik, terutama untuk pertanian tropika. Salah satu produk pertanian tropika Indonesia yang menjadi andalan adalah produk pertanian segar dalam bentuk sayuran dan buah-buahan. Potensi sumber daya lahan pertanian mendukung pengembangan agribisnis berbasis tanaman karena lahan pertanian di Indonesia yang menyebar mulai dari dataran rendah sampai dataran tinggi dengan beragam kondisi agroekosistem.

Tanah merupakan salah satu sumberdaya alam yang dibutuhkan oleh manusia yang dapat dimanfaatkan untuk berbagai macam aktivitas guna memenuhi kebutuhan hidupnya. Tanah sebagai sumberdaya yang digunakan untuk keperluan pertanian dapat bersifat sebagai sumberdaya yang dapat pulih (reversible) dan dapat pula sebagai sumberdaya yang dapat habis [1]. Dalam pertanian tanah mempunyai fungsi utama sebagai sumber unsur hara yang dibutuhkan untuk pertumbuhan tanaman dan sebagai tempat tumbuh dan berpegangnya akar serta tempat penyimpanan air yang sangat diperlukan untuk kelangsungan hidup tanaman. Namun seiring berjalannya waktu, aktivitas manusia dalam memenuhi kebutuhan hidupnya membawa dampak negatif terhadap lingkungan. Salah satu dampak negatif akibat aktivitas manusia adalah turunnya kualitas tanah akibat pencemaran limbah yang dihasilkan oleh manusia, baik limbah rumah tangga, industri dan lalu lintas. Salah satu faktor pencemaran tanah yang paling dominan adalah limbah logam berat.

Tanah lapisan atas terkena logam berat yang berupa mineral magnetik seperti magnetite $\left(\mathrm{Fe}_{3} \mathrm{O}_{4}\right)$, hematite $\left(\alpha-\mathrm{Fe}_{2} \mathrm{O}_{3}\right)$ dan maghemite $\left(\gamma-\mathrm{Fe}_{2} \mathrm{O}_{3}\right)$ [2]. Partikel magnetik dapat diperoleh dengan dilakukan proses pemisahan partikel magnetik dengan tanah lapisan atas yang tercemar dengan menggunakan Iron Sand Separator dan
magnetNeodymium Iron Boron (NdFeB). Pengukuran induksi magnetik dari tanah lapisan atas menggunakan Magnetic Probe Pasco PS-2162.

Besaran yang digunakan untuk menentukan sifat kemagnetan dari suatu bahan yaitu tingkat kemagnetan, suseptibilitas magnetik dan suseptibilitas massa. Hubungan antara nilai suseptibilitas magnetik dan kandungan logam berat disekitar jalan raya di perkotaan sudah banyak diteliti oleh beberapa peneliti terdahulu. Hasil penelitian mereka menunjukkan bahwa nilai suseptibilitas magnetik semakin besar ketika tanah semakin terkontaminasi oleh logam berat seperti logam Fe. Penelitian untuk menentukan sifat magnetik pasir dan debu di sepanjang jalan perlu diteliti pada penelitian ini untuk menentukan nilai tingkat kemagnetan, suseptibilitas magnetik dan suseptibilitas massa dari partikel pasir dan debu yang berada dipinggir jalan sepanjang jalan Kartama Kota Pekanbaru. Nilai ini dapat menjelaskan jenis partikel magnetik yang terkandung di dalam pasir dan debu.

\section{METODE PENELITIAN}

Metode yang digunakan dalam penelitian ini adalah metode eksperimen untuk menentukan sifat magnetik khususnya tingkat kemagnetan, suseptibilitas magnetik dan suseptibilitas massa.

\section{a. Prosedur Pengambilan Sampel}

Pengambilan sampel pada penelitian ini dilakukan di sepanjang Jalan Kartama Pekanbaru. Sampel diambil di 16 titik lokasi berupa pasir dan debu. Sampel 1 sampai 6 diambil berbentuk zig-zag dan sampel 7 (a, b, c, d, dan e) dan sampel 8 (a, b, c, d, dan e) diambil sebagai fungsi jarak menjauhi jalan (sampel 7 ke arah selatan dan sampel 8 ke arah utara). Jumlah pasir dan debu yang digunakan pada penelitian ini dapat dilihat pada Tabel 1 dan Tabel 2. 
Tabel 1. Jumlah banyaknya sampel sepanjang jalan Kartama Pekanbaru

\begin{tabular}{|c|c|c|c|c|}
\hline No. & Titik Lokasi & $\begin{array}{c}\text { Jumlah } \\
(\mathrm{kg})\end{array}$ & Keterangan & Titik Koordinat \\
\hline 1 & $\begin{array}{llr}\text { Sampel } & 1 & \text { (Depan } \\
\text { Pusat } & \text { Bimbingan }\end{array}$ & 2,00 & Pasir + Debu & $\begin{array}{c}0^{\circ} 26^{\prime} 37.6 \text { " LU dan } \\
101^{\circ} 25^{\prime} 39.6 \text { " BT }\end{array}$ \\
\hline 2 & $\begin{array}{l}\text { Belajar Mutiara) } \\
\text { Sampel } 2 \text { (Seberang } \\
\text { Toserba Era) }\end{array}$ & 2,00 & Pasir + Debu & $\begin{array}{c}0^{\circ} 26^{\prime} 37.6 \text { " LU dan } \\
101^{\circ} 25^{\prime} 56.0 ” \text { " BT }\end{array}$ \\
\hline 3 & $\begin{array}{lr}\text { Sampel } & \text { (Depan } \\
\text { Foto } & \text { studio } \\
\text { aCreative) } & \end{array}$ & 2,00 & Pasir + Debu & $\begin{array}{c}0^{\circ} 26^{\prime} 36.9^{\prime \prime} \text { LU dan } \\
101^{\circ} 26^{\prime} 13.2^{\prime \prime} \mathrm{BT}\end{array}$ \\
\hline 4 & $\begin{array}{lcr}\text { Sampel } & 4 & \text { (Depan } \\
\text { Usaha } & \text { Kayu } & \text { Dimas } \\
\text { Jaya) } & & \end{array}$ & 2,00 & Pasir + Debu & $\begin{array}{c}0^{\circ} 26^{\prime} 37.0^{\prime \prime} \mathrm{LU} \text { dan } \\
101^{\circ} 26^{\prime} 29.6^{\prime \prime} \mathrm{BT}\end{array}$ \\
\hline 5 & $\begin{array}{l}\text { Sampel } 5 \text { (Simpang } \\
\text { Gg. Sepakat) }\end{array}$ & 2,00 & Pasir + Debu & $\begin{array}{c}0^{\circ} 26^{\prime} 36.5^{\prime \prime} \text { LU dan } \\
101^{\circ} 26^{\prime} 45.1^{\prime \prime} \mathrm{BT}\end{array}$ \\
\hline 6 & $\begin{array}{llr}\text { Sampel } & 6 & \text { (Depan } \\
\text { Sarapan } & \text { Pagi } & \text { Buk } \\
\text { Elvi) } & & \\
\end{array}$ & 2,00 & Pasir + Debu & $\begin{array}{c}0^{\circ} 26^{\prime} 33.7^{\prime \prime} \mathrm{LU} \text { dan } \\
101^{\circ} 26^{\prime} 56.0^{\prime \prime} \mathrm{BT}\end{array}$ \\
\hline
\end{tabular}

Tabel 2. Jumlah banyaknya pengambilan sampel sebagai fungsi jarak dari jalan Kartama Pekanbaru

\begin{tabular}{|c|c|c|c|c|c|c|}
\hline \multirow{2}{*}{$\begin{array}{c}\text { No } \\
1 \\
\end{array}$} & \multicolumn{3}{|c|}{ Titik Lokasi } & \multirow{2}{*}{$\begin{array}{c}\begin{array}{c}\text { Jumlah } \\
(\mathrm{kg})\end{array} \\
1,66\end{array}$} & \multirow{2}{*}{$\begin{array}{c}\text { Keterangan } \\
\text { Pasir + Debu }\end{array}$} & \multirow{2}{*}{$\begin{array}{l}\text { Titik Koordinat } \\
0^{\circ} 26^{\prime} 37.3^{\prime \prime} \mathrm{LU}\end{array}$} \\
\hline & Arah & Selatan & Sampel 7a & & & \\
\hline & (Depan & & Sampel 7b & 1,60 & Pasir + Debu & dan $101^{\circ} 26^{\prime} 05.2^{\prime \prime}$ \\
\hline & Bengkel & Las & Sampel 7c & 1,20 & Pasir + Debu & BT \\
\hline & Rizky) & & Sampel 7d & 1,20 & Pasir + Debu & \\
\hline & & & Sam & 1,09 & Pasir & \\
\hline \multirow[t]{5}{*}{2} & Arah & Utara & Sampel 8a & 1,54 & Pasir + Debu & $0^{\circ} 26^{\prime} 37.6 ” \mathrm{LU}$ \\
\hline & (Depan & Servis & Sampel 8b & 1,62 & Pasir + Debu & dan $101^{\circ} 25^{\prime} 51.5^{\prime \prime}$ \\
\hline & Sofa dan & Kursi) & Sampel 8c & 1,62 & Pasir + Debu & BT \\
\hline & & & Sam & 1,66 & Pasir & \\
\hline & & & Sampel 8e & 1,66 & Pasir + Debu & \\
\hline
\end{tabular}

\section{b. Pemisahan dengan Meggunakan Iron Sand Separator}

Sampel pasir dan debu yang sudah diambil dari 16 titik lokasi di sepanjang jalan Kartama kota Pekanbaru kemudian ditimbang untuk mengetahui massa sampelnya $\left(\mathrm{M}_{\S}\right)$ dengan menggunakan timbangan duduk.

Sampel yang sudah ditimbang kemudian dipisahkan partikel magnetiknya dengan menggunakan alat Iron Sand Separator yang hasilnya berupa konsentrat I. Pemisahan dilakukan sebanyak 1 kali untuk masingmasing sampel. Konsentrat pasir dan debu tersebut selanjutnya ditimbang massa konsentratnya $\left(\mathrm{M}_{\mathrm{K}}\right)$ menggunakan timbangan digital dan diukur nilai induksi magnetik totalnya ( $\mathrm{B}_{\mathrm{T}}$ konsentrat $\left.\mathrm{I}\right)$ dengan arus $6 \mathrm{~A}$ dan jarak tetap $(1 \mathrm{~mm})$ dari ujung tengah solenoid. 


\section{c. Pemisahan Konsentrat dengan menggunakan Magnet Neodymium Iron Boron (NdFeB)}

Sampel yang telah melewati proses Iron Sand Separator yang berupa konsentrat I kemudian sampel dipisahkan kembali menggunakan magnet Neodymium Iron Boron $(\mathrm{NdFeB})$. Konsentrat yang diperoleh dari hasil pemisahan magnet Neodymium Iron Boron ( $\mathrm{NdFeB}$ ) berupa konsentrat II. Konsentrat tersebut selanjutnya ditimbang massa konsentratnya $\left(\mathrm{M}_{\mathrm{k}}\right)$ dan diukur nilai induksi magnetik totalnya $\left(\mathrm{B}_{\mathrm{T}}\right.$ konsentrat II) dengan arus $6 \mathrm{~A}$ dan jarak tetap $(1 \mathrm{~mm})$ dari ujung tengah solenoid.

\section{d. Penentuan Sifat Kemagnetan}

Setelah mendapatkan konsentrat atau partikel magnetik yang dihasilkan dari pemisahan mengggunakan Iron Sand Separator dan magnet Neodymium Iron Boron maka dapat ditentukan tingkat kemagnetan (Magnetic Degree) dengan cara membandingkan massa konsentrat dengan massa sampel. Sebelum pengukuran terhadap induksi magnetik dari konsentrat, maka langkah pertama adalah pembuatan solenoid yang berdiameter $3 \mathrm{~cm}$ dan panjang $10 \mathrm{~cm}$ dengan jumlah lilitan 2000 lilitan lalu menghubungkannya dengan arus listrik. Kemudian dapat dilakukan pengukuran induksi magnetik dengan menggunakan Magnetic Probe Pasco PS-2162 sebagai fungsi arus dan jarak. Pengukuran Induksi Magnetik Solenoida dilakukan dengan empat tahapan, yaitu pengukuran induksi magnetik solenoid tanpa inti $\left(\mathrm{B}_{0}\right)$, pengukuran induksi magnetik solenoid dengan inti sampel $\left(\mathrm{B}_{\mathrm{T}}\right.$ sampel), pengukuran induksi magnetik solenoid dengan inti konsentrat $\mathrm{I}\left(\mathrm{B}_{\mathrm{T}}\right.$ konsentrat I) dan pengukuran induksi magnetik solenoid dengan inti konsentrat II ( $\mathrm{B}_{\mathrm{T}}$ konsentrat $\left.\mathrm{II}\right)$. Berdasarkan data yang diperoleh dari hasil pengukuran induksi magnetik maka suseptibilitas magnetik dapat ditentukan.

Sampel dan konsentrat yang telah diukur besar induksi magnetiknya akan dilakukan pengukuran volume dengan menggunakan gelas ukur. Hasil pengukuran volume dan massa digunakan untuk mengetahui rapat massa yang merupakan salah satu parameter untuk menentukan suseptibilitas massa.

\section{HASIL DAN PEMBAHASAN}

\section{a. Tingkat Kemagnetan (Magnetic Degree)}

Tingkat kemagnetan dari masingmasing sampel dan konsentrat ditunjukkan pada Gambar 1. Berdasarkan data pada Gambar 1. terlihat bahwa sampel yang tinggi tingkat kemagnetannya adalah sampel yang berasal dari sampel $7 \mathrm{e}$ dengan tingkat kemagnetannya adalah 2,54\%, sedangkan sampel yang rendah tingkat kemagnetannya adalah sampel yang berasal dari sampel 8e yaitu $0,163 \%$. Tingginya tingkat kemagnetan dari suatu sampel dipengaruhi adanya kandungan logam berat seperti $\mathrm{Fe}$ yang terakumulasi di dalam pasir dan debu yang disebabkan oleh gas buang kendaraan bermotor [3], serta adanya aktivitas lain dari masyarakat seperti adanya bengkel-bengkel. Semakin tinggi sampel terkontaminasi maka semakin tinggi tingkat kemagnetan dari sampel tersebut. 


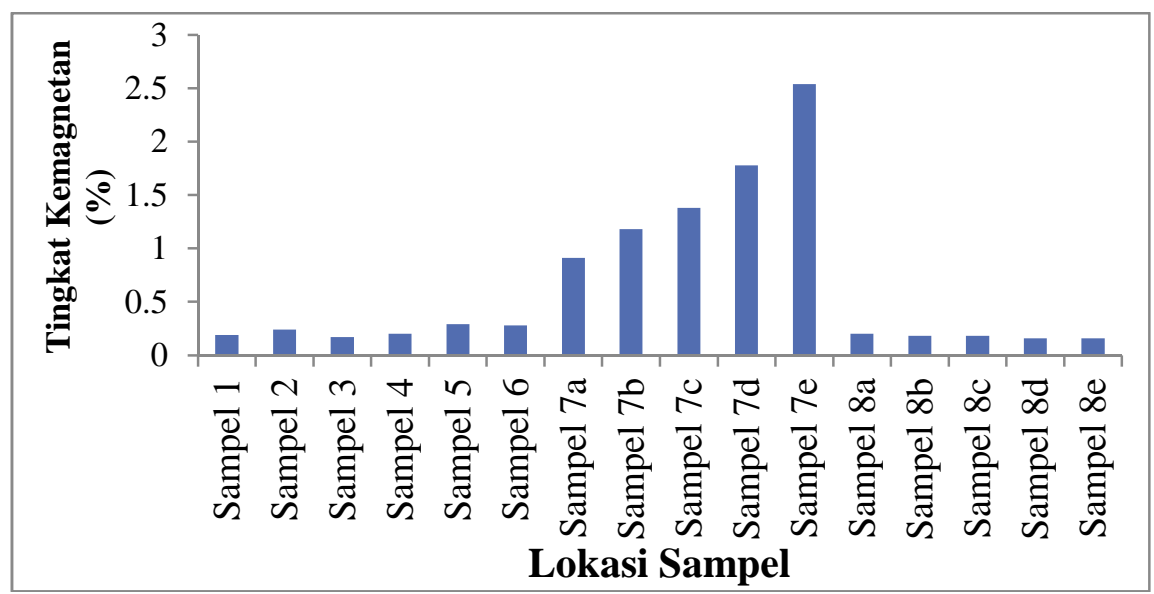

Gambar 1. Grafik Tingkat Kemagnetan Masing-masing Lokasi.

\section{b. Suseptibilitas Magnetik}

Nilai suseptibilitas magnetik ditunjukkan pada Gambar 2, Gambar 3, dan Gambar 4.

Berdasarkan Gambar 2, Gambar 3. dan Gambar 4. Terlihat bahwa nilai suseptibilitas magnetik pada konsentrat II jauh lebih besar jika dibandingkan dengan nilai suseptibilitas magnetik pada sampel dan konsentrat I. Tinginya nilai suseptibilitas magnetik pada konsentrat II disebabkan karena meningkatnya jumlah partikel magnetik dalam konsentrat II. Hasil yang diperoleh ini sesuai dengan hasil peneliti terdahulu [4].
Dapat dilihat bahwa nilai suseptibilitas magnetik terendah dari konsentrat II berada pada sampel 2 yaitu sebesar $3125,52 \times 10^{-5}$ dan nilai suseptibilitas tertinggi berada pada sampel 7 b yaitu sebesar $9158,12 \times 10^{-5}$. Secara keseluruhan nilai suseptibilitas magnetik konsentrat II berada pada interval nilai mineral Ilmenite ( $\mathrm{FeTi}_{3}$; Antiferromagnetik) dengan rentang nilai $(220-38000) \times 10^{-5}$ kecuali pada sampel 2, 4, 8a dan 8c merupakan nilai mineral Hematite $\left(\mathrm{Fe}_{2} \mathrm{O}_{3}\right.$; Antiferromagnetik) dengan rentang nilai $(50-4000) \times 10^{-5}[5]$.

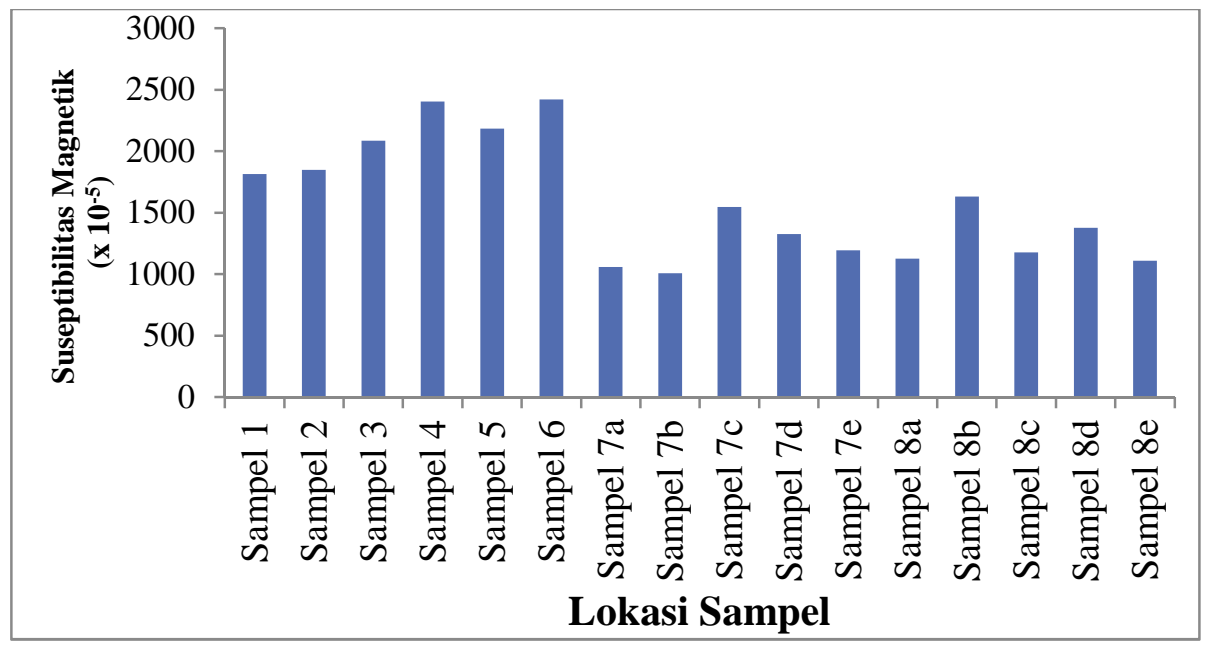

Gambar 2. Grafik Nilai Suseptibilitas Magnetik Pasir dan Debu (sebelum pemisahan) dari Setiap Sampel. 


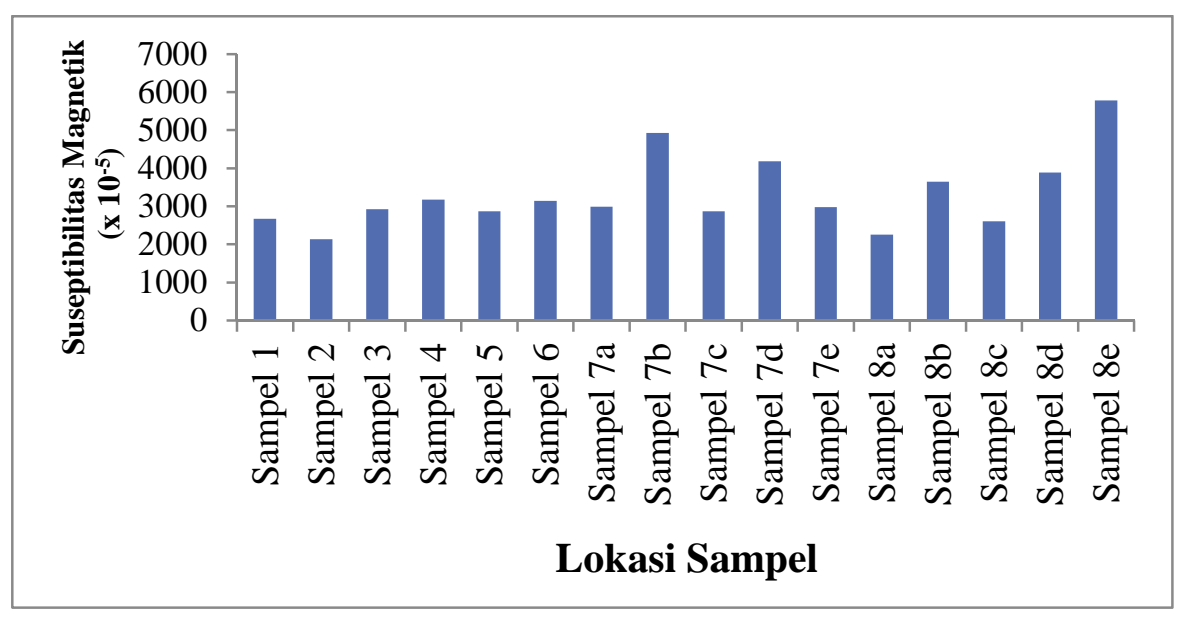

Gambar 3. Grafik Nilai Suseptibilitas Magnetik Konsentrat I (Setelah Pemisahan dengan Iron Sand Separator).

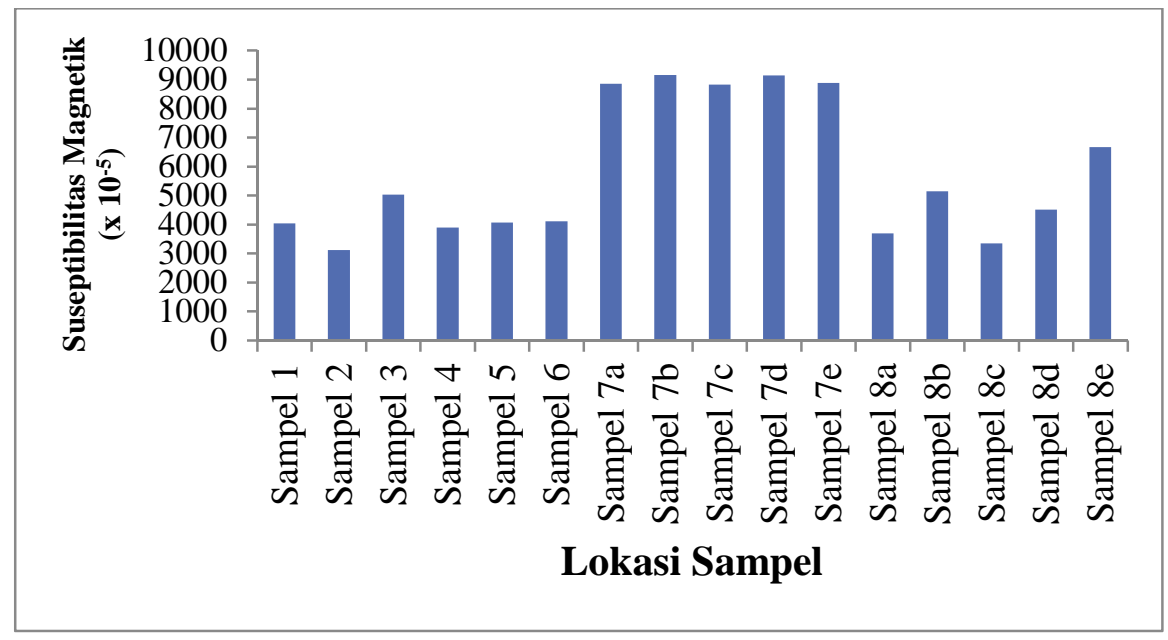

Gambar 4. Grafik Nilai Suseptibilitas Magnetik Konsentrat II (Setelah Pemisahan dengan Magnet Neodymium Iron Boron (NdFeB).

\section{c. Suseptibilitas Massa}

Nilai suseptibilitas massa masingmasing sampel dan konsentrat ditunjukkan pada Tabel 3. Berdasarkan Tabel 3. terlihat bahwa nilai suseptibilitas massa pada konsentrat II tertinggi berada di lokasi $7 \mathrm{e}$ dengan nilai $2244,77 \times 10^{-\frac{u}{\mathrm{~K}}} \quad$ sementara nilai suseptibilitas massa terendah berada pada sampel 2 dengan nilai 679,45 $\times 10^{-8} \frac{\mathrm{m}^{\sharp}}{\mathrm{K}}$. Secara keseluruhan nilai suseptibilitas massa yang dominan lebih tinggi ada pada lokasi 7a sampai 7e, ini di karenakan lokasi pengambilan sampel ada di depan bengkel las. Secara otomatis logam berat seperti besi $(\mathrm{Fe})$ sudah terakumulasi di dalam pasir dan debu di sekitar bengkel las tersebut. Nilai suseptibilitas massa konsentrat II yang diperoleh dari masing-masing sampel berada dalam interval nilai Ilmenite $\left(\mathrm{FeTiO}_{3} ;\right.$ Antiferromagnetik) dengan rentang nilai (46-80000) $\times 10^{-4} \frac{\mathrm{m}^{\sharp}}{\mathrm{K}}[5]$. 
Tabel 3. Nilai Suseptibilitas Massa Pasir dan Debu (Sebelum Pemisahan), Nilai Suseptibilitas Massa Konsentrat I ( Setelah Pemisahan dengan Iron Sand Separator) dan Nilai Suseptibilitas Massa Konsentrat II ( Setelah Pemisahan dengan Magnet Neodymium Iron Boron $(\mathrm{NdFeB}))$ pada arus tetap $6 \mathrm{~A}$.

\begin{tabular}{|c|c|c|c|}
\hline TitikLokasi & $\begin{array}{c}X m \\
\times 10^{-\bullet} \\
\left(\frac{m^{\Xi}}{k}\right) \\
\text { Pasir dan Debu }\end{array}$ & $\begin{array}{c}X m \\
\times 10^{-\square} \\
\left(\frac{m^{ \pm}}{k}\right)\end{array}$ & $\begin{array}{c}\chi_{\mathrm{m}} \\
\times 10^{-8} \\
\left(\frac{\mathrm{m}^{\mathrm{s}}}{\mathrm{K}}\right) \\
\text { Konsentrat II }\end{array}$ \\
\hline Sampel 1 & 1139,23 & 600,40 & 960,04 \\
\hline Sampel 2 & 1175,83 & 502,14 & 679,45 \\
\hline Sampel 3 & 1291,82 & 662,99 & 1131,62 \\
\hline Sampel 4 & 1456,36 & 747,27 & 938,61 \\
\hline Sampel 5 & 1331,20 & 662,07 & 991,82 \\
\hline Sampel 6 & 1532,49 & 729,07 & 970,91 \\
\hline Sampel 7a & 662,45 & 673,67 & 2098,51 \\
\hline Sampel 7b & 635,28 & 1094,11 & 2129,749 \\
\hline Sampel 7c & 1016,44 & 631,51 & 2051,63 \\
\hline Sampel 7d & 801,14 & 940,24 & 2166,18 \\
\hline Sampel 7e & 742,43 & 658,01 & 2244,77 \\
\hline Sampel 8a & 774,34 & 536,11 & 924,22 \\
\hline Sampel 8b & 1057,06 & 868,19 & 1266,50 \\
\hline Sampel 8c & 824,31 & 623,11 & 815,61 \\
\hline Sampel 8d & 958,87 & 922,01 & 1153,11 \\
\hline Sampel 8e & 783,81 & 1396,26 & 1635,07 \\
\hline
\end{tabular}

\section{KESIMPULAN}

Berdasarkan hasil penelitian yang telah dilakukan maka dapat diambil kesimpulan yaitu tingkat kemagnetan (Magnetic Degree) nilainya berada dalam interval $0,16 \%$ sampai $2,54 \%$. Artinya nilai ini cukup potensial untuk membuat tanah di sepanjang Jalan Kartama terkontaminasi secara magnetik.

Nilai Suseptibilitas magnetik konsentrat lebih besar daripada nilai suseptibilitas sampel. Tingginya nilai ini disebabkan karenameningkatnya jumlah partikel magnetik di dalam konsentrat. Nilai suseptibilitas magnetik konsentrat yaitu sebesar 3125,52 $\times 10^{-5}$ sampai $9158,12 \times 10^{-5}$. Nilai ini berada dalam interval $(220-38000) \times 10^{-5}$ yang merupakan interval mineral Ilmenite
(FeTi0 ${ }_{3}$;Antiferromagnetik). Berdasarkan nilai suseptibilitas massa konsentrat yang diperoleh, maka sampel pasir dan debu yang di ambil di enam belas titik lokasi berada dalam interval (46-80000) $\times 10^{-}-\frac{m^{\sharp}}{k}$ yang merupakan interval mineral Ilmenite $\left(\mathrm{FeTiO}_{3}\right.$; Antiferromagnetik).

\section{DAFTAR PUSTAKA}

1. Santoso, P. \& Ahmad, S. (1991). Dampak Pembangunan Terhadap Tanah, Tataguna Lahan dan Tata Ruang. Bandung.

2. Yulianto, A. S., Bijaksana, \& Loeksmato, W. (2002). Karakterisasi magnetik dari Pasir Besi Cilacap. Jurnal Fisika 
Himpunan Fisika Indonesia. Vol. A5 (0527), 2002.

3. Al-Khasman, O. A. (2004). Heavy metal distribution in dust, street dust and soils from the work place in Karak Industrial Estate. Jordan. Atmospheric Environment. 38, 6803-6812.

4. Anggraini, E. P. (2018). Penentuan sifat magnetik pasir dan debu sepanjang jalan
H.R. Soebrantas Pekanbaru menggunakan Magnetic Probe Pasco PS-2162. Skripsi Fisika,Universitas Riau.

5. Hunt, C. P., Moskowitz, B. M., \& Banerjee, S. K. (1995). Magnetic Properties of Rocks and Minerals. Washington: American Geophysical Union. 